\title{
Artigo/Article
}

\section{Hibridização reversa e sequenciamento na genotipagem do vírus da hepatite C}

\author{
Reverse hybridization and sequencing for genotyping the hepatitis $\mathrm{C}$ virus \\ Patrícia Martinez Levada ${ }^{1}$, Camila Fernanda Verdichio de Moraes $^{2}$, Silvia Maria Corvino ${ }^{1}$, Rejane Maria \\ Tommasini Grotto ${ }^{1,2}$, Giovanni Faria Silva ${ }^{2}$ Maria Inês de Moura Campos Pardini ${ }^{1,2}$
}

\begin{abstract}
RESUMO
Introdução: Os métodos de genotipagem do vírus da hepatite $\mathrm{C}$ têm sido muito discutidos. $\mathrm{O}$ objetivo deste trabalho foi comparar as metodologias de hibridização reversa e sequenciamento direto para a genotipagem do vírus da hepatite C. Métodos: Noventa e uma amostras de plasma de pacientes assistidos na Faculdade de Medicina de Botucatu da Universidade Estadual Paulista foram utilizadas. A genotipagem por hibridização reversa foi realizada utilizando o kit comercial INNO-LiPA ${ }^{\circledR}$ v.1.0. O sequenciamento direto foi efetuado em sequenciador automático utilizando protocolos in house. Resultados: A genotipagem por sequenciamento direto mostrou-se eficiente na resolução dos resultados inconclusivos pelo kit comercial. O kit mostrou resultados errôneos em relação à subtipagem viral. Além disso, a genotipagem por sequenciamento direto revelou um erro do kit com relação à determinação genotípica questionando a eficiência do método também para a identificação do genótipo viral. Conclusões: A genotipagem realizada por meio de sequenciamento direto permite uma maior acurácia na classificação viral quando comparada à hibridização reversa

Palavras-chaves: Vírus da hepatite C. Genotipagem. Hibridização reversa. Sequenciamento direto.
\end{abstract}

\begin{abstract}
Introduction: The methods for genotyping the hepatitis $\mathrm{C}$ virus have been much discussed. The aim of this study was to compare the methodologies of reverse hybridization and direct sequencing for genotyping the hepatitis $\mathrm{C}$ virus. Methods: Ninety-one plasma samples from patients attended at the Botucatu Medical School, São Paulo State University, were used. Genotyping by reverse hybridization was performed using the INNO-LiPA ${ }^{\circledR}$ v.1.0 commercial kit. Direct sequencing was performed in an automated sequencer using in-house protocols. Results: Genotyping by direct sequencing was shown to be efficient for resolving cases that had remained inconclusive after using the commercial kit. The kit showed erroneous results in relation to virus subtyping. Moreover, direct sequencing revealed an error of the kit regarding the genotypic determination, thereby raising doubts about the efficiency of reverse hybridization for identifying the virus genotype. Conclusions: Genotyping by direct sequencing allowed greater accuracy of virus classification than did reverse hybridization.
\end{abstract}

Key-words: Hepatitis C virus. Genotyping. Reverse hybridization. Direct sequencing.

1. Divisão Hemocentro, Faculdade de Medicina de Botucatu, Universidade Estadual Paulista, Botucatu, SP 2. Departamento de Clínica Médica, Faculdade de Medicina de Botucatu, Universidade Estadual Paulista, Botucatu, SP.

Endereço para correspondência: Dra. Maria Inês M.C. Pardini. Divisão Hemocentro/FMB/UNESP. Distrito Rubião Júnior s/n, 18618-970 Botucatu, SP.

Tel: 5514 3811-6041 ramal 220; Fax: 5514 3811-6041 ramal 205

e-mail:inespardini@gmail.com

Recebido para publicação em 16/07/2009

Aceito em 19/01/2010

\section{INTRODUÇÃO}

O padrão ouro na determinação dos genótipos e subtipos do vírus da hepatite $\mathrm{C}$ (VHC) é a análise da sequência genômica viral completa. No entanto, devido a maior praticidade e rapidez, outros procedimentos são normalmente adotados na rotina laboratorial ${ }^{1}$. A genotipagem do VHC pode examinar várias regiões do genoma. A região mais usada pelos testes comerciais de genotipagem é a $5^{\prime}$ UTR devido à facilidade de amplificação com iniciadores universais. Entretanto, alguns autores ${ }^{1,2}$ têm questionado a eficiência desta região quanto à genotipagem e, principalmente, quanto à subtipagem viral. A genotipagem por hibridização reversa, distribuída sob o nome comercial de Line Probe Assay (INNO-LiPA ${ }^{\circledR}$ ) (Siemens Medical Solutions Diagnostics), é muito utilizada em vários países. Este teste utiliza sondas específicas para diferentes partes do genoma viral imobilizadas em uma membrana de nitrocelulose ${ }^{2,3}$. Existem atualmente duas versões do $L i P A(1.0$ e 2.0). A primeira versão contém sondas para a região 5'UTR do genoma viral e a última, além destas, inclui sondas para a região genômica core do $\mathrm{VHC}^{3}$.

Os métodos de genotipagem, assim como a região do genoma viral a ser utilizada, constituem temas de discussão na comunidade científica ressaltando a importância de trabalhos que avaliem comparativamente as metodologias em uso para a determinação dos genótipos e subtipos do vírus $\mathrm{C}$. $\mathrm{O}$ presente trabalho teve por objetivo comparar as metodologias de hibridização reversa (kit INNO-LiPA ${ }^{\circledR}$ v.1.0) e sequenciamento direto das regiões $5^{\prime} U T R$, NS5B e core do genoma do VHC como ferramentas para a determinação dos genótipos e subtipos virais.

\section{MÉTODOS}

Neste trabalho, foram utilizadas 91 amostras de plasma de pacientes atendidos na Faculdade de Medicina de Botucatu da Universidade Estadual Paulista (UNESP). A genotipagem por hibridização 
reversa foi realizada com o kit INNO-LiPA ${ }^{\circledR}$ v.1.0 (Siemens Medical Solutions Diagnostics. A genotipagem por sequenciamento direto foi efetuada segundo protocolos in house. A extração do RNA viral foi realizada a partir do plasma utilizando o kit QIAamp Viral RNA Mini Kit (Qiagen) segundo as especificações. Em seguida, realizouse uma etapa de transcrição reversa utilizando o kit High Capacity (Applied Biosystem) segundo recomendações. Para todas as amostras de $c D N A$ obtidas foram realizadas amplificações por Nested-PCR (Polymerase Chain Reaction) das regiões 5'UTR e NS5B. Nos casos em que ocorreram falhas de amplificação para a região NS5B foi feita a $P C R$ do fragmento 5'UTR-core. As reações de amplificação da região 5'UTR foram realizadas utilizando os primers PTC1, NCR2, PTC3 e NCR4 segundo protocolos descritos na literatura ${ }^{4}$. Foram utilizadas duas estratégias de amplificação da região NS5B. Na primeira estratégia, os primers 242 e 243 já descritos anteriormente ${ }^{5}$ foram utilizados. Na segunda estratégia de amplificação, foram utilizados os primers PR3 e PR4 segundo protocolo previamente descrito ${ }^{1}$. A segunda reação de $P C R$ de ambas as estratégias foi realizada com os primers $\mathrm{PR} 3$ e PR5 segundo metodologia já descrita ${ }^{1}$. A amplificação da região 5'UTR-core foi realizada utilizando os primers Q1, AQ1, Q2 e AQ2 segundo condições detalhadas anteriormente ${ }^{6}$. A reação de marcação fluorescente foi efetuada utilizando o kit ABI Prism Big Dye ${ }^{T M}$ Terminator Cycle Sequencing v3.1 (Applied Biosystems) e a eletroforese em gel de poliacrilamida desnaturante a $6 \%$ em aparelho automático ABI 377 (Applied Biosystems) segundo recomendações do fabricante. A qualidade dos cromatogramas foi avaliada com o software Phred ${ }^{7}$ utilizando como critério de validação o escore de 20. As sequências de boa qualidade foram posteriormente analisadas, por meio do software $\mathrm{BioEdit}^{8}$ com a finalidade de construir sequências consenso. As sequências consenso resultantes foram então genotipadas pelo $H C V$-Blast disponível no banco de dados The Los Alamos HCV Sequence (http://hcv.lanl.gov) ${ }^{9}$.

\section{Ética}

Este trabalho teve aprovação do Comitê de Ética em Pesquisa da Faculdade de Medicina de Botucatu, Universidade Estadual Paulista - UNESP (Ofício n¹66/08 - CEP) em 05 de maio de 2008.

\section{RESULTADOS}

Os resultados da genotipagem pelo kit comercial e por sequenciamento direto das três regiões genômicas do VHC encontram-se detalhados na Tabela 1. Algumas amostras não puderam ser genotipadas por sequenciamento direto devido a falhas na etapa de amplificação. Noventa e uma amostras foram amplificadas para a região 5'UTR e 62 para NS5B. A região 5'UTRcore mostrou-se eficiente na amplificação de 28 das amostras que falharam para NS5B.

\section{DISCUSSÃO}

Os resultados inconclusivos pelo INNO-LiPA ${ }^{\circledR}$ puderam ser solucionados em $100 \%$ dos casos pela metodologia de sequenciamento direto. Todas estas amostras tiveram seus genótipos determinados pelo sequenciamento da região $5^{\prime} U T R$. Cinco delas também puderam ser genotipadas pelo sequenciamento de uma segunda região do genoma viral (NS5B ou 5'UTR-core) confirmando os resultados obtidos com o sequenciamento da região 5'UTR com relação à determinação genotípica. Com relação à subtipagem, entretanto, uma amostra subtipada como $1 \mathrm{a} / 1 \mathrm{~b}$ pela região $5^{\prime} U T R$ foi determinada como $1 \mathrm{~b}$ pelo sequenciamento da região $5^{\prime} U T R$ core, discrepância que será abordada mais adiante neste trabalho. Foi proposto que a eficiência da hibridização reversa seria limitada nos casos de amostras com grande número de variantes virais, pois haveria necessidade de condições muito elevadas de estringência ${ }^{10}$. No presente estudo, três das amostras referidas acima exibiram sobreposição de picos em algumas posições da sequência de nucleotídeos da região 5'UTR (Figura 1), o que provavelmente significa a presença de variantes virais.

Para avaliar possibilidade de mistura dos subtipos $1 \mathrm{a}$ e $1 \mathrm{~b}$ determinada pelo INNO-LiPA ${ }^{\circledR}$, em dez amostras, verificou-se a eficiência da posição 243 de $5^{\prime}$ UTR. Segundo Stuyver et a ${ }^{11}$, uma adenina (A) nesta posição seria característica do subtipo 1a enquanto que a presença de uma guanina $(G)$ determinaria o subtipo $1 \mathrm{~b}$. Foram utilizadas, em paralelo, as genotipagens por uma segunda região. Uma das dez amostras apresentou sobreposição dos picos de A e G na posição 243 de 5'UTR (Figura 2), o que caracterizaria uma mistura 1a/1b. Nenhuma destas amostras pôde ser amplificada para a região $N S 5 B$, utilizando-se, portanto, a genotipagem por sequenciamento da região $5^{\prime} U T R$-core. A subtipagem pela região 5'UTR-core confirmou os resultados da análise de 5'UTR para sete amostras divergindo em relação a duas amostras subtipadas como $1 \mathrm{~b}$ por 5'UTR que foram subtipadas como 1a por 5'UTR-core e uma amostra subtipada como $1 \mathrm{a} / 1 \mathrm{~b}$, caracterizada como 1 a por $5^{\prime} U T R$ core. Além das amostras já referidas uma terceira amostra genotipada apenas como 1 pelo kit comercial exibiu sobreposição dos picos de $\mathrm{A}$ e G na posição 243 da região 5'UTR. A análise da região 5'UTR-core para esta amostra resultou no subtipo 1a. Além das discrepâncias já relatadas até o momento, cinco amostras genotipadas como $1 \mathrm{~b}$ pelo sequenciamento da região NS5B apresentaram uma A na posição 243 de 5'UTR e seis amostras subtipadas como 1a por meio das regiões NS5B ou 5'UTR-core apresentaram uma G na posição 243 de 5 'UTR. Tais discrepâncias mostram que a posição 243 de 5 'UTR não foi eficaz como critério para a discriminação entre os subtipos la e $1 b$.

Houve total concordância entre a genotipagem por sequenciamento direto das amostras genotipadas como 3 a pelo INNO-LiPA ${ }^{\circledR}$ v.1. Para as amostras classificadas como 2 pelo kit comercial, a genotipagem realizada por sequenciamento direto da região 5'UTR não foi totalmente conclusiva entre os subtipos $2 \mathrm{a}$ e $2 \mathrm{c}$ já que as sequências da região $5^{\prime} U T R$ são idênticas para ambos os subtipos ${ }^{12}$.A genotipagem realizada por sequenciamento direto da região NS5B pôde subtipar conclusivamente as amostras como $2 \mathrm{c}$.

Um dos pacientes componentes deste estudo revelou estar infectado pelo genótipo 5 do VHC segundo a genotipagem pelo kit comercial INNO-LiPA ${ }^{\circledR}$. O isolado viral obtido da amostra de plasma deste paciente foi genotipado como $1 \mathrm{~b}$ por sequenciamento direto das regiões 5'UTR e 5'UTR-core. Todos os testes foram realizados novamente e os resultados discrepantes foram confirmados. Tais resultados são importantes não apenas pela questão epidemiológica, mas principalmente pela definição da conduta terapêutica. É importante salientar ainda que as três sondas adicionais para a região core do genoma viral incluídas na versão 2.0 do kit comercial INNO-LiPA ${ }^{\circledR}$ não solucionariam o problema aqui destacado já que apenas permitem uma maior precisão na determinação do genótipo 6 e melhor distinção entre os subtipos 1a e $1 b$. 
TABELA 1 - Genótipos e subtipos determinados pelas metodologias de hibridização reversa ( LiPA) e sequenciamento direto das regiões $5^{\prime} U T R, N S 5 B$ e 5 'UTR-core sendo $n^{\circ}=$ número ou nome da amostra e inc $=$ inconclusivo.

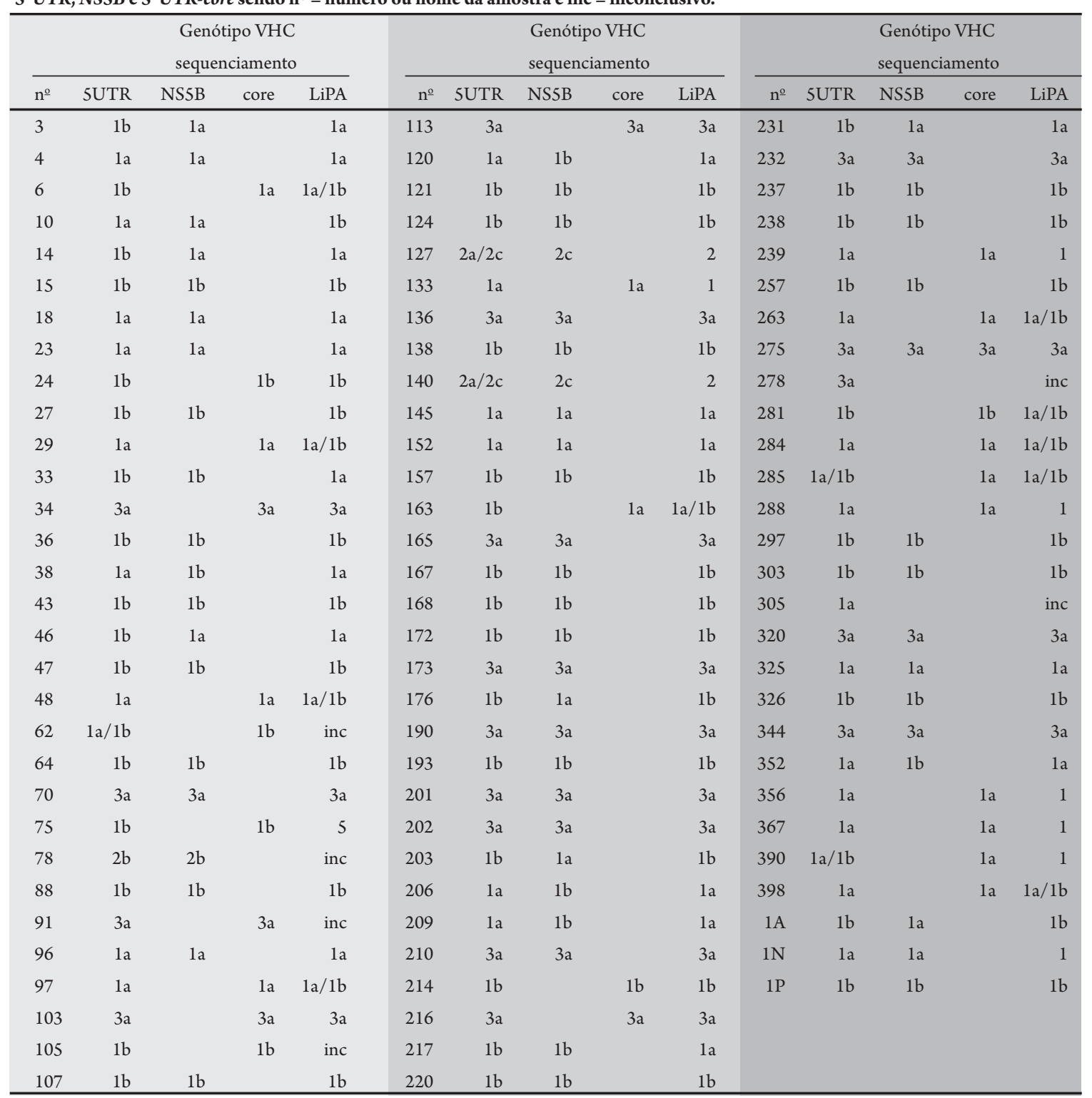

VHC: vírus da hepatite C, genótipos do VHC: $1: a, b, a / b ; 2: b, c ; 3: a ; 5$.

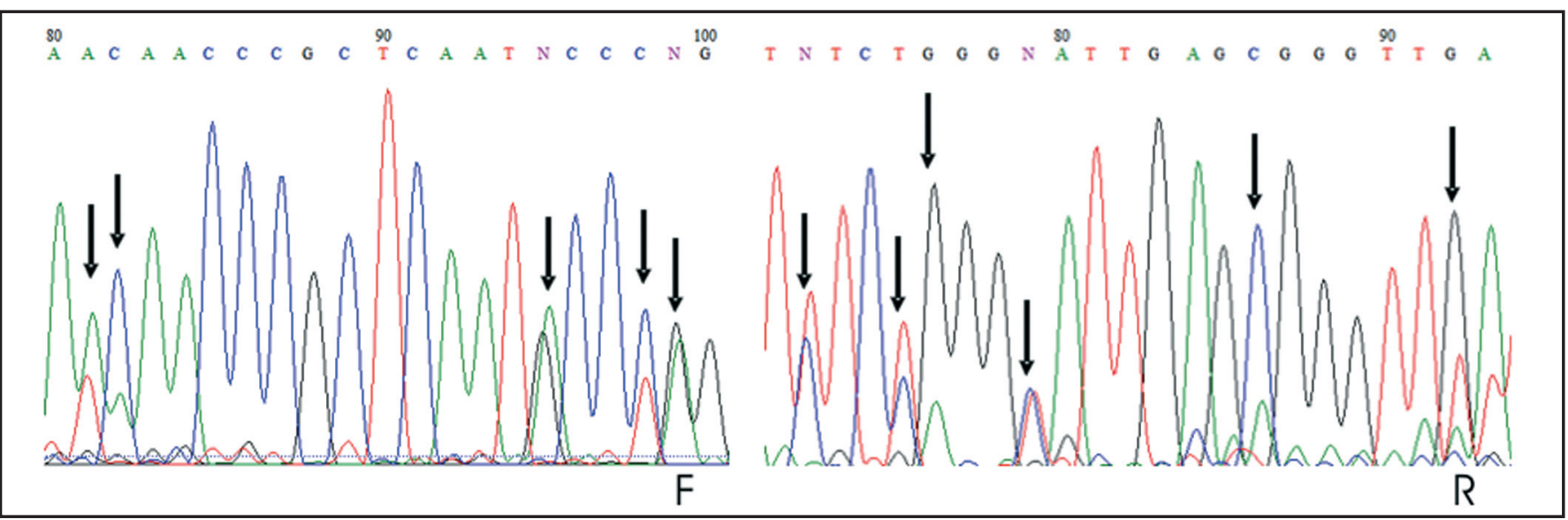

FIGURA 1 - Cromatogramas das sequências da região genômica 5 'UTR do VHC obtidos de amostra com resultado inconclusivo pela genotipagem com o kit INNO-LiPA ${ }^{\circledR}$ v.1.0. F: sequência obtida com o primer forward; R: sequência obtida com o primer reverse. As sequências exibem sobreposições de picos em algumas posições (indicadas pela setas). 


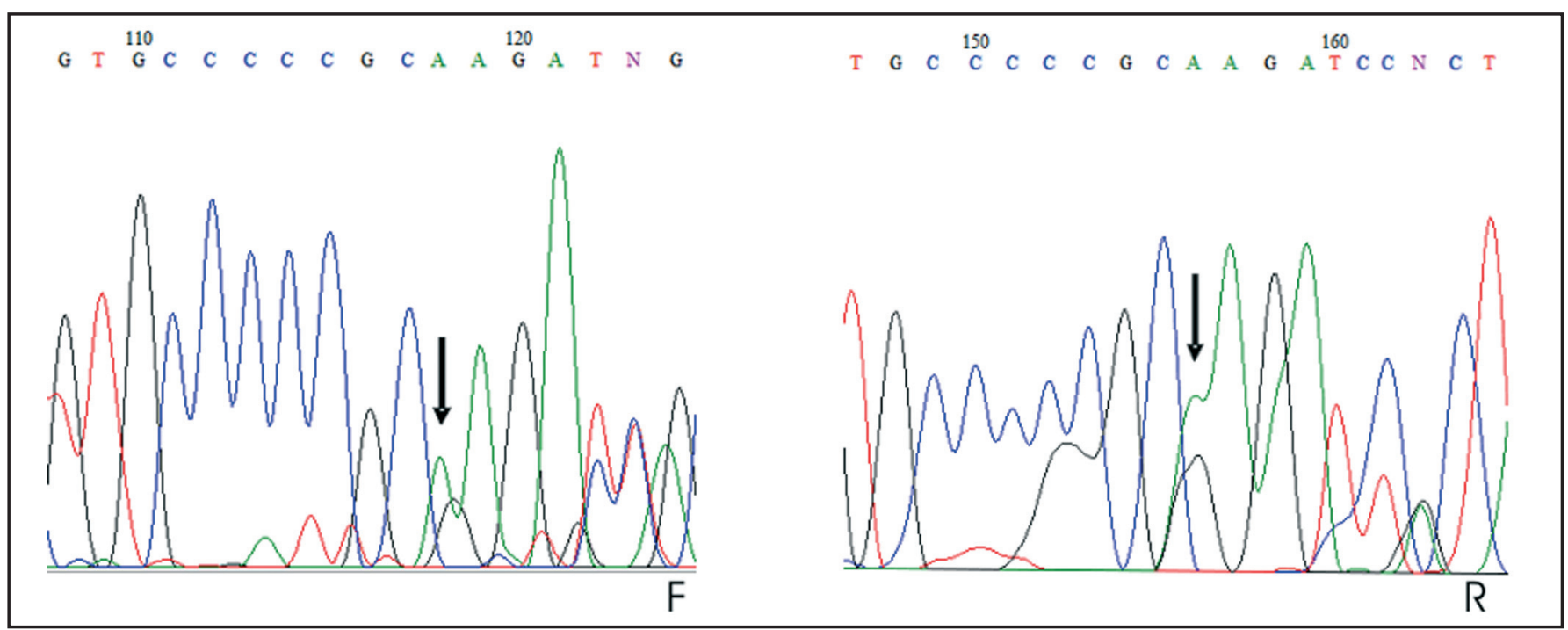

FIGURA 2 - Cromatogramas de sequências exibindo sobreposições de picos de adenina (verde) e guanina (preto) na posição 243 da região 5 'UTR do genoma do VHC (posição indicada pela seta) de uma amostra previamente classificada como 1a/1b pela genotipagem com kit comercial INNO-LiPA ${ }^{\circledR}$ v.1.0. F: sequência obtida com o primer forward; R: sequência obtida com o primer reverse.

Por meio da análise dos resultados, obtidos neste trabalho, concluiu-se que: a inclusão de uma região genômica viral com maior diversidade genética, adicional à $5^{\prime} U T R$, garantiu uma maior precisão na determinação dos genótipos e subtipos virais; a região 5'UTR-core, utilizada no casos de falha de amplificação da região NS5B, mostrou eficiência na determinação dos genótipos e subtipos virais; o sequenciamento direto foi eficaz na solução dos casos de resultados inconclusivos pela hibridização reversa realizada com o kit; o kit comercial INNO-LiPA ${ }^{\circledR} \mathrm{v} .1 .0$ produziu resultados errôneos com relação à subtipagem do $\mathrm{VHC}$; a genotipagem por sequenciamento direto revelou ainda um erro do kit com relação à determinação genotípica, influenciando a conduta terapêutica e questionando a eficiência do método comercial também quanto à identificação dos tipos virais.

\section{CONFLITO DE INTERESSE}

Os autores declaram não haver nenhum tipo de conflito de interesse no desenvolvimento do estudo.

\section{SUPORTE FINANCEIRO}

Rede Estadual de Hepatites Virais, Fundação de Amparo à Pesquisa do Estado de São Paulo (FAPESP), DOCT Confecções.

\section{REFERÊNCIAS}

1. Sandres-Sauné K, Deny P, Pasquier C, Thibaut V, Duverlie G, Izopet $\mathrm{J}$. Determining hepatitis $\mathrm{C}$ genotype by analyzing the sequence of NS5b region. J Virol Methods 2003;109:187-193.

2. Ansaldi F, Torre F, Bruzzone BM, Picciotto A, Crovari P, Icardi G. Evaluation of a new hepatitis $\mathrm{C}$ vírus sequencing assay as a routine method for genotyping. J Med Virol 2001;63:17-21.

3. Cavalheiro NP. Hepatitis C: genotyping. Braz J Infect Dis 2007;11:25-27.

4. Garson JA, Tedder RS, Briggs M, Tuke P, Glazebrook JA, Trute A, Parker D, Barbara JA, Contreras M, Aloysius S. Detection of hepatitis $\mathrm{C}$ viral sequences in blood donations by nested polymerase chain reaction and predition of infectivity. Lancet 1990;335:1419-1422.

5. Enomoto N, Takada A, Nakao T, Date T. There are two major types of hepatitis C virus in Japan. Biochem Biophys Res Commun 1990;170:1021-1025.

6. Verma V, Chakravarti A. Comparison of 5 'noncoding-core with noncoding regions of HCV by RT-PCR: Importance and clinical implications. Curr Microbiol 2008;57: 206-211.

7. Ewing B, Hillier L, Wendl MC, Green, P. Base-calling of automated sequencer traces using phred. I. Accuracy Assessment. Genome Res 1998;8:175-185.

8. Hall TA. BioEdit: a user-friendily biological sequence alignment editor and analysis program for Windows 95/98/NT. Nucleic Acids Symp Ser 1999;41: 95-98.

9. Kuiken C, Yusim K, Boykin, Richardson R. The Los Alamos hepatitis C sequence database. Bioinformatics 2005;21:379-384.

10. Stuyver L, Van Arnhem W, Wyseur A, Hernandez F, Delaporte E, Maertens G. Classification of hepatitis $C$ viruses based on phylogenetic analysis of the envelope 1 and nonstructural 5B regions and identification of five additional subtypes. Proc Natl Acad Sci USA 1994;91:10134-10138.

11. Stuyver L, Rossau A, Wyseur M, Duhamel B, Vanderborght H, Van Heuverswyn $\mathrm{H}$, Maertens G. Typing of hepatitis $\mathrm{C}$ virus isolates and characterization of new subtypes using a line probe assay. J Gen Virol 1993;74:1093-1102.

12. Le Pogam S, Dubois F, Christen R, Raby C, Cavicchini A, Goudeau A. Comparison of DNA enzyme immunoassay and line probe assays (Inno-LiPA I and II) for hepatitis C virus genotyping. J Clin Microbiol 1998; 36: 14611463. 